\title{
Cardiovascular risk management in type 2 diabetes of more than 10-year duration: Results of Polish ARETAEUS2-Grupa Study
}

\author{
Wiktoria Leśniak ${ }^{1}$, Małgorzata M. Bała ${ }^{1}$, Ewa Płaczkiewicz-Jankowska², \\ Roman Topór-Mądry ${ }^{3,4}$, Miłosz Jankowski ${ }^{1}$, Jacek Sieradzki ${ }^{5}$, Waldemar Banasiak ${ }^{6}$; \\ for the ARETAEUS2 Study Group* \\ ${ }^{1} 2^{\text {nd }}$ Department of Internal Medicine, Jagiellonian University Medical College, Krakow, Poland \\ ${ }^{2}$ Polish Institute of Evidence Based Medicine, Krakow, Poland \\ ${ }^{3}$ IBMed, Institute of Medical Studies, Krakow, Poland \\ ${ }^{4}$ Institute of Public Health, Jagiellonian University Medical College, Krakow, Poland \\ ${ }^{5}$ Department of Metabolic Diseases, Jagiellonian University Medical College, Krakow, Poland \\ ${ }^{6}$ Heart Disease Centre, Military Clinical Hospital, Wroclaw, Poland \\ *Under the patronage of Diabetes Poland
}

\begin{abstract}
Background: ARETAEUS 1 study showed that a great majority of patients with type 2 diabetes mellitus (T2DM) of short duration did not meet all of the treatment goals. Since then the treatment goals in T2DM have been changed. The aim of the ARETAEUS 2-Grupa Study was to assess cardiovascular $(\mathrm{CV})$ risk management and meeting treatment goals in the population of T2DM of more than 10-year duration.
\end{abstract}

Methods: ARETAEUS2-Grupa was a cross-sectional questionnaire-based study conducted in Poland in 2012. Randomly selected physicians recruited 1,740 patients with T2DM diagnosed more than 10 years before the study.

Results: Lipid treatment goals were met respectively: for total cholesterol in $34.5 \%$ of all patients, triglycerides in 53.8\%, low density lipoprotein cholesterol (LDL-C) in 26.5\% and high density lipoprotein cholesterol (HDL-C) in 38.2\%. Most of patients with and without coronary artery disease were receiving aspirin (90.3\% and 60\%, respectively) and statins $(84.4 \%$ and $67.7 \%$, respectively). The current blood pressure (BP) goal (140/90 $\mathrm{mm} \mathrm{Hg}$ ) was met in $43.5 \%$ of patients and the previous goal $(<130 / 80 \mathrm{~mm} \mathrm{Hg})$ in 12.4\%. The patients were mainly treated with $\geq 3$ antihypertensive drugs. All treatment goals (for $\mathrm{HbA1c}, \mathrm{BP}$ and $\mathrm{LDL}-\mathrm{C}$ ) were reached only by $8.2 \%$ of patients, any two goals by $26.3 \%$ of patients, one goal by $39.8 \%$ of patients, none by $25.6 \%$ of patients.

Conclusions: The new less restrictive treatment goals are reached more frequently but still much is to be done in the field of clinical practice guidelines implementation and CV prevention in T2DM population. (Cardiol J 2015; 22, 2: 150-159)

Key words: cross-sectional study, cardiovascular risk, risk factors control, diabetes mellitus type 2 , diabetes mellitus complications, clinical practice guidelines

Address for correspondence: Wiktoria Leśniak, $\mathrm{MD}, \mathrm{PhD}, 2^{\text {nd }}$ Department of Internal Medicine, Jagiellonian University Medical College, ul. Skawińska 8, 31-066 Kraków, Poland, tel: +48 122934 235, fax: +48 122934030 ,

e-mail: lesniak@mp.pl

Received: 20.05.2014

Accepted: 22.08.2014 


\section{Introduction}

The increasing prevalence of diabetes mellitus (DM) worldwide has led to a situation where approximately 360 million people had DM in 2011, of whom more than $95 \%$ were diagnosed with type 2 DM (T2DM). Over $60 \%$ of people with T2DM develop cardiovascular disease (CVD), a more severe and costly complication than retinopathy. Thus, CVD risk should be given a higher priority in T2DM population. The problem of CVD risk in diabetes is noticed as very important in Europe and that is why European Society of Cardiology (ESC) in collaboration with the European Association for the Study of Diabetes developed clinical practice guidelines on diabetes, pre-diabetes, and CVD (last update in 2013) [1]. The management of cardiovascular $(\mathrm{CV})$ risk in diabetes is also discussed in other ESC documents [2, 3].

In 2009, the ARETAEUS 1 study was conducted and it showed that a great majority of patients with T2DM of short duration did not meet all of the treatment goals as recommended in the current practice guidelines [4, 5]. In 2011, Diabetes Poland [6] updated its recommended goals in diabetes treatment, and in 2012, ESC [2] updated its guidelines on cardiovascular prevention. Adherence to the updated guidelines has not been systematically assessed.

The main study aims were: 1 ) to assess the pharmacotherapy of T2DM patients and 2) to assess the degree to which the diabetic control criteria recommended in the current clinical practice guidelines developed by the Diabetes Poland [6, 7] (and ESC [2]) are met. This paper reports on CV risk factors prevalence and $\mathrm{CV}$ risk management in the population with T2DM lasting for more than 10 years).

\section{Methods}

Detailed description of the ARETAEUS2-Grupa study design, protocol, questionnaire, inclusion criteria for the study, recruitment procedures of physicians and their patients and sample size calculations was published previously [8]. Briefly, ARETAEUS2-Grupa was a cross-sectional questionnaire-based study conducted in Poland (April-June 2012). The study included two groups of patients with T2DM: 1) diagnosed within the last 2 years and 2 ) diagnosed more than 10 years before the study commencement.

Treatment goal definitions from both Diabetes Poland [6, 7, 9] and ESC [1-3] guidelines were used. Diabetes Poland guidelines define treat- ment goals in T2DM patients as: glycated hemoglobin $\mathrm{A} 1 \mathrm{c}(\mathrm{HbA} 1 \mathrm{c}) \leq 7 \%$, blood pressure $(\mathrm{BP})$ $<140 / 90 \mathrm{~mm} \mathrm{Hg}$ (this threshold was changed from $130 / 80 \mathrm{~mm} \mathrm{Hg}$ in 2011), total cholesterol $<4.5 \mathrm{ml} / \mathrm{L}$, low density lipoprotein cholesterol (LDL-C) $<2.6 \mathrm{mmol} / \mathrm{L}(<1.8 \mathrm{mmol} / \mathrm{L}$ if coronary artery disease $[\mathrm{CAD}]$ is present), high density lipoprotein cholesterol (HDL-C) $>1.0 \mathrm{mmol} / \mathrm{L}$ in men (and $>1.3$ in women), triglycerides (TG) $<1.7 \mathrm{mmol} / \mathrm{L}$. ESC treatment goals are different in the aspect of BP $(<140 / 80$ [2] or $<140 / 85 \mathrm{~mm} \mathrm{Hg}[1,3])$ and LDL-C level $<2.6 \mathrm{mmol} / \mathrm{L}(<1.8 \mathrm{mmol} / \mathrm{L}$ in very high risk patients defined as CAD or DM with one or more $\mathrm{CV}$ risk factors and/or target organ damage).

This paper concerns only patients with T2DM lasting > 10 years, participating in ARATAEUS2-Grupa Study, while the data on CV risk management in patients with T2DM of short duration will be reported separately.

\section{Statistical analysis}

We compared proportions of patients achieving treatment goals in the subgroups with $\chi^{2}$ test or Fischer's exact test (when the expected values in any of the cells of a contingency table were below 5). For the comparison of the means the t-test was used (for normal distribution), and the Mann-Whitney U test and Kruskal-Wallis test (for non-normal distribution of the variable). The distribution was estimated on the basis of skewness coefficient and graphical picture. The t-test for equal or non-equal variances was used depending on the result of the Levene's test. All statistical analyses were conducted using SPSS v 18.0.

\section{Results}

The patient and physician characteristics and the results related to diabetes control was described elsewhere [10]. Sixty per cent of all patients had HbA1c level above 7.0\%.

Mean age of patients was $68 \pm 10$ years, $54 \%$ were female, mean body mass index (BMI) was $30.6 \pm 4.9 \mathrm{~kg} / \mathrm{m}^{2}, 48 \%$ had BMI $>30 \mathrm{~kg} / \mathrm{m}^{2}$, $68.5 \%$ were diagnosed with diabetes $>10-15$ years before, $17.5 \%-\geq 15-20$ years before and $14 \%-$ $>20$ years before.

$\mathrm{CV}$ risk factors were present in great majority of patients participating in the study: according to the physician report $97.4 \%$ patients had hypertension or received antihypertensive drugs (excluding beta-blockers after acute coronary syndrome [ACS]), 83.1\% - lipid disorders, $18.1 \%$ - history of ACS, $48.5 \%$ - stable CAD, $8.9 \%$ - history of stroke, $10.7 \%$ - history of transient ischemic 
Table 1. Coincidence of cardiovascular risk factors in patients with type 2 diabetes mellitus lasting for more than 10 years.

\begin{tabular}{|c|c|}
\hline Variable & In overall population, $\%(n=1,737)$ \\
\hline Diabetes + hypertension ${ }^{a}$ & 91.7 \\
\hline Diabetes + hypertension $^{\mathrm{a}}+$ lipid disorders $^{\mathrm{a}}$ & 78.7 \\
\hline 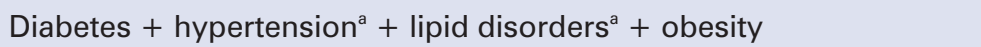 & 41.0 \\
\hline Diabetes + hypertension $^{\mathrm{a}}+$ lipid disorders ${ }^{\mathrm{a}}+$ obesity + ex-smoking & 13.2 \\
\hline 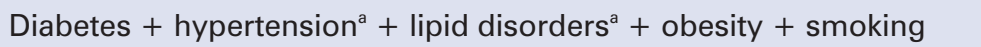 & 5.7 \\
\hline Diabetes + hypertension ${ }^{\mathrm{b}}$ & 93.4 \\
\hline Diabetes + hypertension $^{\mathrm{b}}+$ lipid disorders $^{\mathrm{a}}$ & 79.5 \\
\hline 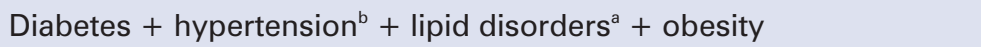 & 41.3 \\
\hline 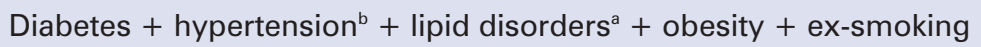 & 13.1 \\
\hline 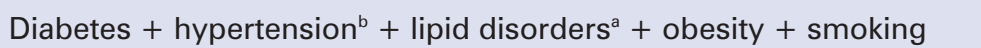 & 5.8 \\
\hline
\end{tabular}

Number in brackets - number of valid questionnaires; ${ }^{a}$ reported by physician; ${ }^{b}$ reported by physician or blood pressure $\geq 140 / 90 \mathrm{~mm} \mathrm{Hg}$

Table 2. Lipid level control and lipid lowering drugs in patients with type 2 diabetes mellitus lasting for more than 10 years.

\begin{tabular}{|c|c|c|c|c|c|}
\hline \multirow[t]{2}{*}{ Variable } & \multirow{2}{*}{$\begin{array}{c}\text { In overall } \\
\text { population, } \\
\%\end{array}$} & \multicolumn{2}{|c|}{$\begin{array}{l}\text { In patients using } \\
\text { statins }\end{array}$} & \multirow{2}{*}{$\begin{array}{l}\text { In patients with } \\
\text { the diagnosis } \\
\text { of lipid disorders } \\
\text { or taking hypo- } \\
\text { lipidemic drugs }\end{array}$} & \multirow{2}{*}{$\begin{array}{c}\text { In patients without } \\
\text { the diagnosis } \\
\text { of lipid disorders } \\
\text { and not taking hypo- } \\
\text { lipidemic drugs }\end{array}$} \\
\hline & & Yes & No & & \\
\hline Total cholesterol & $N=1,668$ & & & $N=1,405$ & $N=248$ \\
\hline$<4.5 \mathrm{mmol} / \mathrm{L}$ & $34.5(576)$ & & & $32.0(450)$ & $46.4(115)$ \\
\hline$\geq 4.5 \mathrm{mmol} / \mathrm{L}$ & $65.5(1,092)$ & & & $68.0(955)^{*}$ & $53.6(133)^{*}$ \\
\hline LDL-C & $N=1,432$ & $N=1,111$ & $N=288$ & $N=1,208$ & $N=210$ \\
\hline $\begin{array}{l}<2.6 \mathrm{mmol} / \mathrm{L} \text { or if CAD } \\
<1.8 \mathrm{mmol} / \mathrm{L}\end{array}$ & $26.5(379)$ & $24.1(268)$ & $34.7(100)$ & $24.0(290)$ & $38.6(81)$ \\
\hline $\begin{array}{l}\geq 2.6 \mathrm{mmol} / \mathrm{L} \text { or if } \mathrm{CAD} \\
\geq 1.8 \mathrm{mmol} / \mathrm{l}\end{array}$ & $73.5(1,053)$ & 75.9 (843) & $65.3(188)$ & $76.0(918)^{*}$ & $61.4(129)^{*}$ \\
\hline $\begin{array}{l}<2.6 \mathrm{mmol} / \mathrm{L} \text { or if } \\
\text { very high CV risk } \\
<1.8 \mathrm{mmol} / \mathrm{L}\end{array}$ & $15.2(217)$ & $15.3(170)$ & $14.2(41)$ & $14.6(176)$ & $18.1(38)$ \\
\hline $\begin{array}{l}\geq 2.6 \mathrm{mmol} / \mathrm{L} \text { or if } \\
\text { very high CV risk } \\
\geq 1.8 \mathrm{mmol} / \mathrm{L}\end{array}$ & $84.8(1,215)$ & 84.7 (941) & $85.8(247)$ & $85.4(1,032)$ & $81.9(172)$ \\
\hline HDL-C & $N=1,434$ & & & $N=1,218$ & $N=202)$ \\
\hline $\begin{array}{l}>1.0 \mathrm{mmol} / \mathrm{L} \text { males, } \\
>1.3 \mathrm{mmol} / \mathrm{L} \text { females }\end{array}$ & $38.2(548)$ & & & $39.5(481)$ & $30.7(62)$ \\
\hline $\begin{array}{l}<1.0 \mathrm{mmol} / \mathrm{L} \text { males } \\
<1.3 \mathrm{mmol} / \mathrm{L} \text { females }\end{array}$ & $61.8(886)$ & & & $60.5(737)^{*}$ & $69.3(140)^{*}$ \\
\hline Triglycerides & $N=1,629)$ & & & $\mathrm{N}=1,383)$ & $\mathrm{N}=230)$ \\
\hline$<1.7 \mathrm{mmol} / \mathrm{L}$ & $53.8(877)$ & & & $49.8(689)$ & $76.5(176)$ \\
\hline$\geq 1.7 \mathrm{mmol} / \mathrm{L}$ & $46.2(752)$ & & & $50.2(694)^{*}$ & $23.5(54)^{*}$ \\
\hline
\end{tabular}

Numbers in brackets - number of valid questionnaires; *significant difference between patients taking and not taking hypolipidemic drug (statin, fibrate); CV — cardiovascular; CAD — coronary artery disease; LDL-C — low density lipoprotein cholesterol; HDL-C — high density lipoprotein cholesterol

attack, $53 \%$ were smokers and $31 \%$ ex-smokers. Mean systolic/diastolic arterial pressure in participants with diagnosed hypertension was $139 \pm$ $\pm 15 / 81 \pm 10 \mathrm{~mm} \mathrm{Hg}$ and among those without such diagnosis $127 \pm 11 / 76 \pm 7 \mathrm{~mm} \mathrm{Hg}$. The coinci- dence of various risk factors was very frequent (Table 1).

The mean lipid levels are presented in Table 2 . Total cholesterol treatment goal $(<4.5 \mathrm{mmol} / \mathrm{L})$ was met in $34.5 \%$ of all patients, TG treatment goal 
$(<1.7 \mathrm{mmol} / \mathrm{L})$ in $53.8 \%$, LDL-C treatment goal $(<2.6 \mathrm{mmol} / \mathrm{L}$ or if $\mathrm{CAD}<1.8 \mathrm{mmol} / \mathrm{L}$ - criterion defined in Diabetes Poland guidelines) in $26.5 \%$ (in $15.2 \%$ if $<1.8 \mathrm{mmol} / \mathrm{L}$ threshold was used for all patients with very high $\mathrm{CV}$ risk according to ESC guidelines $[1,3]$ ) and HDL-C treatment goal $(>1.0 \mathrm{mmol} / \mathrm{L}$ in men and $>1.3 \mathrm{mmol} / \mathrm{L}$ in women) in $38.2 \%$. There were significant differences in the numbers of patients achieving these targets between patients with the diagnosis of lipid disorders (or taking hypolipidemic drugs) and without such a diagnosis (or not taking drugs). There were no significant differences between the subgroups using and not using statins (LDL-C treatment goal defined in Diabetes Poland guidelines was reached in $24.1 \%$ vs. $34.7 \%$ patients, respectively).

The use of acetylsalicylic acid (ASA), statins, fibrates, and beta-blockers in the studied patients is shown in Table 3. Most of patients with and without CAD were receiving ASA $(90.3 \%$ and $60 \%$, respectively) and statins (84.4\% and $67.7 \%$, respectively). Ninety per cent of patients with a history of myocardial infarction received beta-blocker (Table 3). The use of medications in different age subgroups is presented in Figure 1.

Percentages of patients falling into different categories of BP levels are shown in Table 4.

Regarding BP control, the treatment goal outlined in the last 3 editions of Diabetes Poland guidelines $[6,7,9]$ (i.e. 140/90 $\mathrm{mm} \mathrm{Hg}$ ) was met in $43.5 \%$ of the overall population. The percentage was significantly higher in the subgroup of patients without the diagnosis of hypertension and not taking antihypertensive drugs as compared with patients with the diagnosis of hypertension or taking antihypertensive drugs (79.4\% vs. $39.6 \%$; Fig. 2A). The more restricted goal of BP below $130 / 80 \mathrm{~mm} \mathrm{Hg}$ (which was used by Diabetes Poland in the guidelines until 2010 [11] when all study participants have already had T2DM) was achieved in $12.4 \%$ of patients. The patients were mainly treated with $\geq 3$ antihypertensive drugs (Fig. 2B). The majority received angiotensin converting enzyme inhibitor, beta-blocker, diuretic and calcium channel blocker; other drugs were used less frequently (Table 5). Combination antihypertensive drugs were used in $14.9 \%$ of patients.

All treatment goals $(\mathrm{HbA} 1 \mathrm{c} \leq 7.0 \%, \mathrm{BP}$ $<140 / 90 \mathrm{~mm} \mathrm{Hg}$ and LDL-C $<2.6 \mathrm{mmol} / \mathrm{L}$ $[<1.8 \mathrm{mmol} / \mathrm{L}$ if CAD]) were reached only by $8.2 \%$ of patients, any two goals by $26.3 \%$ of patients (HbA1c and BP goals in 14.9\%, HbA1c and LDL-C goals in $5.8 \%$, BP and LDL-C goals in 5.6\%), one goal by $39.8 \%$ of patients (HbA1c goal in $13.6 \%$, BP goal in $18.2 \%$, LDL-C goal in $8.0 \%$ ), none by $25.6 \%$ of patients. The percentages of patients reaching three or two goals were smaller if LDL-C treatment goal was defined according to ESC guidelines (4.5\% and $25.2 \%$, respectively). Figure 3 represents the results of the analysis of the number (and type) of treatment goals met in the differently predefined subgroups of patients (with or without previous $\mathrm{CV}$ events; receiving different number of antihypertensive drugs, receiving and not receiving statins and fibrates).

\section{Discussion}

ARETAEUS2-Grupa Study is the first Polish study addressing specifically patients with T2DM of more than 10-year duration. In this paper, the data on $\mathrm{CV}$ risk factors profile and management are presented.

Other Polish studies, OPTIMO [12] and DYNAMIC-2 [13], included respectively $24 \%$ and $16 \%$ of patients with T2DM of more than 10 -year duration. In The Polish Diabetes Registry for adults [14], mean diabetes duration was 9.7 years. Achieving all of the treatment goals (HbA1c, BP and lipid values) was very uncommon in those studies (regardless of the goal definitions), and the proportion of patients achieving one or two of these goals was also unsatisfactory.

We used goal definitions from both Diabetes Poland [6, 7, 9] and ESC [1-3] guidelines which differ in some aspects (see above). Since the time of diagnosis in all patients participating in ARETAEUS2-Grupa Study was described here, the thresholds of good $\mathrm{CV}$ risk control have been changed. Those changes in the treatment goals and the inconsistency between the guidelines of leading scientific societies make the implementation of these guidelines even more difficult, although this cannot be used as an excuse and the only explanation for poor diabetes control. Additionally, some goals are not clearly defined and need ordering special diagnostic tests, which are not so easily available in an outpatient clinic. An example could be the LDL-C level according to ESC guidelines [2], which was less frequently reached (in comparison to more clear goal of LDL-C control according to Diabetes Poland and previous ESC [15] guidelines $-15.2 \%$ vs. $26.5 \%$ ).

The treatment goals are less restrictive now and this is the first survey in which rate of achieving these new goals was studied. Our study shows that they are reached in more patients but the level is still unsatisfactory. We cannot exclude the possibility that physicians do not pay enough atten- 
Table 3. Acetylsalicylic acid (ASA), statins and beta-blockers use in patients with type 2 diabetes mellitus lasting for more than 10 years.

\begin{tabular}{|c|c|}
\hline Variable & $\begin{array}{l}\text { Percent of patients using } \\
\text { the medicine (n) }\end{array}$ \\
\hline Acetylsalicylic acid use & $76.9(1,294)$ \\
\hline$<40$ years $(n=11)$ & $40(2)$ \\
\hline$\geq 40$ years $(n=1,672)$ & $76.4(772)$ \\
\hline Without CAD ( $n=806)$ & $60(284)$ \\
\hline With CAD ( $\mathrm{n}=882$ ) & $90.3(492)$ \\
\hline Without CAD and $<40$ years $(n=10)$ & $30.0(3)$ \\
\hline Without CAD and $\geq 40$ years $(n=789)$ & $62.0(489)$ \\
\hline With CAD and $<40$ years $(n=1)$ & $100.0(1)$ \\
\hline With CAD and $\geq 40$ years $(n=871)$ & $90.9(792)$ \\
\hline Statin use $(n=1,699)$ & $77.5(1,317)$ \\
\hline Without CAD ( $n=805)$ & $67.5(543)^{*}$ \\
\hline With CAD ( $\mathrm{n}=882$ ) & $86.6(764)^{*}$ \\
\hline $\mathrm{LDL}<2.6 \mathrm{mmol} / \mathrm{L}$ or if $\mathrm{CAD}<1.8 \mathrm{mmol} / \mathrm{L}(\mathrm{n}=368)$ & $72.8(268)^{\wedge}$ \\
\hline $\mathrm{LDL} \geq 2.6 \mathrm{mmol} / \mathrm{L}$ or if $\mathrm{CAD} \geq 1.8 \mathrm{mmol} / \mathrm{L}(\mathrm{n}=1,031)$ & $81.8(843)^{\wedge}$ \\
\hline \multicolumn{2}{|l|}{$\mathrm{LDL}<2.6 \mathrm{mmol} / \mathrm{L}$ or if CAD $<1.8 \mathrm{mmol} / \mathrm{L}$ AND } \\
\hline Without CAD ( $\mathrm{n}=257$ ) & $67.7(174)$ \\
\hline With CAD ( $n=109)$ & $84.4(92)$ \\
\hline \multicolumn{2}{|l|}{$\mathrm{LDL} \geq 2.6 \mathrm{mmol} / \mathrm{L}$ or if $\mathrm{CAD} \geq 1.8 \mathrm{mmol} / \mathrm{L}$ AND } \\
\hline Without CAD (n = 402) & $72.6(292)$ \\
\hline With CAD (n = 626) & $87.5(548)$ \\
\hline \multicolumn{2}{|l|}{ LDL control according to ESC guidelines } \\
\hline $\mathrm{LDL}<2.6 \mathrm{mmol} / \mathrm{L}$ or if CAD (or $\geq 1$ risk factor) $<1.8 \mathrm{mmol} / \mathrm{L}(\mathrm{n}=211)$ & $80.6(170)$ \\
\hline $\mathrm{LDL} \geq 2.6 \mathrm{mmol} / \mathrm{L}$ or if $\mathrm{CAD}$ (or $\geq 1$ risk factor) $\geq 1.8 \mathrm{mmol} / \mathrm{L}(\mathrm{n}=1,188)$ & $72.6(941)$ \\
\hline Fibrate use $(n=1,608)$ & $14.5(233)$ \\
\hline Beta-blockers use $(n=1,634)$ & $65.2(1,066)$ \\
\hline Without a history of $\mathrm{MI}(\mathrm{n}=1,331)$ & $59.4(791) \#$ \\
\hline With a history of MI $(n=303)$ & 90.8 (275)\# \\
\hline
\end{tabular}

Numbers in brackets - number of valid questionnaires; * significant difference between patients with and without coronary heart disease $(C A D) ; \wedge$ significant difference between patients with and without lipid control; \#significant difference between patients with and without a history of myocardial infarction (MI); ESC — European Society of Cardiology; LDL — low density lipoprotein

tion to prevention and do not find time to explain to patients its importance, and that patients with chronic disease are tired of all restrictions (life style modifications and multidrug regimens).

It is worth mentioning that $56 \%$ of all patients have $\mathrm{BP}>140 / 90 \mathrm{~mm} \mathrm{Hg}$, although the frequency of using 3 or more antihypertensive agents was high (30.7 and $31.7 \%$, respectively). A substantial change in the number of antihypertensives used in 1 patient is to be noticed during the last decade — in Dynamic II study [13], only $18.4 \%$ of patients received more than 2 of those agents. Therefore, it is possible that the problem of poor BP control is not connected with the number of drugs used but with adjustment of the dose or with patients' compliance. However, the frequency of using combination drugs seems to be too low (14\%); physicians should be encouraged to use them more often, because it may improve compliance [16].

The lipid control in our study participants is similar to that observed in the Polish Diabetes Registry for adults [14] - total cholesterol $<4.5 \mathrm{mmol} / \mathrm{L}$ was present in $34.5 \%$ vs. $32.6 \%$, and $\mathrm{TG}<1.7 \mathrm{mmol} / \mathrm{L}$ in $53.8 \%$ vs. $53.2 \%$ of patients. These data show some improvement as compared to the DEPAC survey [17] performed in Central and Eastern Europe (including Poland) at the time of accession to EU (2004) in which total cholesterol $<4.5 \mathrm{mmol} / \mathrm{L}$ was present in $19.7 \%$ and $\mathrm{TG}$ $<1.7 \mathrm{mmol} / \mathrm{L}$ in $43.5 \%$ of participants. Although the difference could also be attributed to the fact that DEPAC included only secondary care patients, which focuses on patients with advanced diabetic complications and requiring treatment intensifica- 


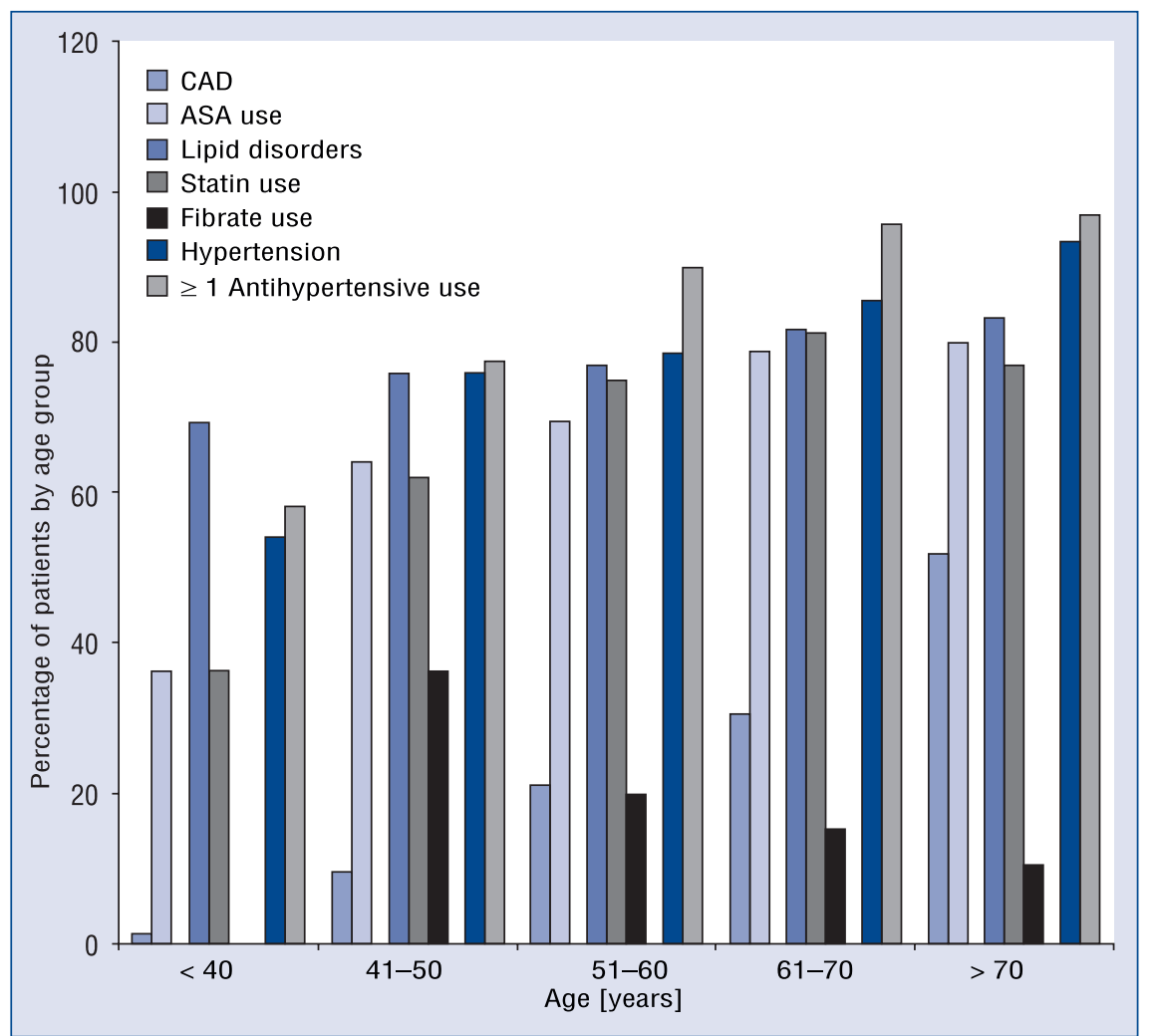

Figure 1. The prevalence of coronary artery disease, lipid disorders and hypertension and the use of medications in different age subgroups; ASA — acetylsalicylic acid; CAD — coronary artery disease.

Table 4. Categories of blood pressure levels in patients with type 2 diabetes mellitus lasting for more than 10 years.

\begin{tabular}{|c|c|c|c|c|c|}
\hline \multirow{2}{*}{$\begin{array}{l}\text { Systolic blood pressure } \\
\text { [mm Hg] }\end{array}$} & \multicolumn{5}{|c|}{ Diastolic blood pressure [mm Hg] } \\
\hline & $\begin{aligned} & <80 \\
(n & =534)\end{aligned}$ & $\begin{array}{c}80-90 \\
(n=756)\end{array}$ & $\begin{array}{c}90-100 \\
(n=335)\end{array}$ & $\begin{array}{l}100-110 \\
(n=88)\end{array}$ & $\begin{array}{c}\geq 110 \\
(n=10)\end{array}$ \\
\hline$<130(n=353)$ & $60.6(214)$ & $38.2(135)$ & $1.1(4)$ & 0.0 & 0.0 \\
\hline $130-140(n=464)$ & $34.1(158)$ & $56.9(264)$ & $9.1(42)$ & 0.0 & 0.0 \\
\hline $140-160(n=720)$ & $20.0(144)$ & $42.5(306)$ & $31.1(224)$ & $6.4(46)$ & 0.0 \\
\hline $160-180(n=160)$ & $10.0(16)$ & $28.8(46)$ & $37.5(60)$ & $18.8(30)$ & $5.0(8)$ \\
\hline$\geq 180(n=26)$ & $7.7(2)$ & $19.2(5)$ & $19.2(5)$ & $46.2(12)$ & $7.7(2)$ \\
\hline
\end{tabular}

tion, our study included both primary and secondary care settings.

It is needed to mention that in the current ACC/AHA guidelines on the treatment of blood cholesterol to reduce atherosclerotic $\mathrm{CV}$ risk in adults, the LDL goals are not defined any more [18]. According to these guidelines, the patients at the age $40-75$ with diabetes and LDL-C level $>70 \mathrm{mg} / \mathrm{dL}(1.8 \mathrm{mmol} / \mathrm{L})$ moderate or high-intensity statin therapy is recommended (dependent on LDL-C level $<$ or $>189 \mathrm{mg} / \mathrm{dL}$ ). Moderate and high doses of statins are defined as in clinical trials. However, this new approach was not accepted by European societies which still recommend that the ESC guidelines are followed [1,2]. There are concerns that without obvious treatment goals the patient compliance can be worse.

The adherence to clinical practice guidelines is better when the recommendations are clear, simple and easy to follow (e.g. using specific drugs in specific clinical situations - ASA in CAD [90.3\% of study participants with CAD received it] or 


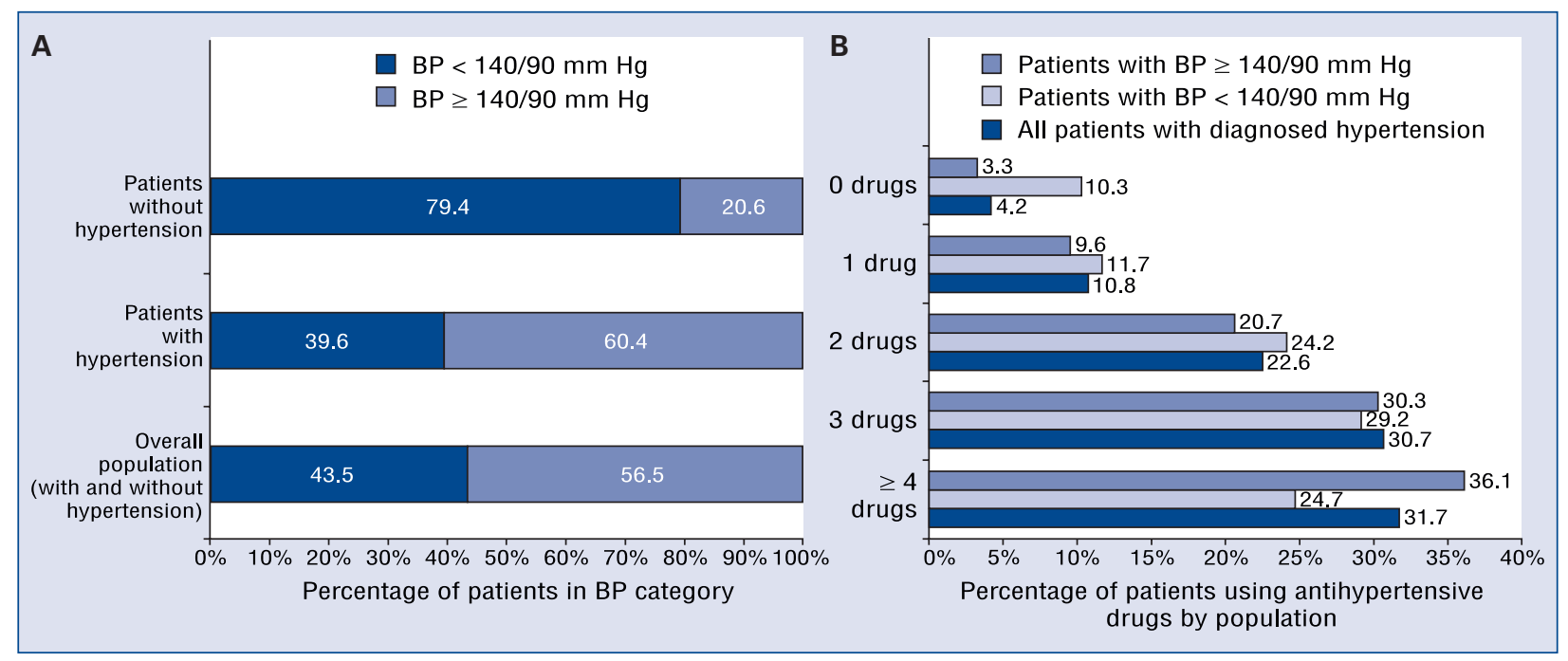

Figure 2. A. Blood pressure (BP) control and previously diagnosed hypertension in patients with type 2 diabetes mellitus lasting > 10 years; B. Number of antihypertensive drugs used in the whole population and the subgroups with elevated and with normal BP.

Table 5. The use of all classes of antihypertensive drugs.

\begin{tabular}{|c|c|c|c|}
\hline \multirow[t]{2}{*}{ Drug class (number of valid questionnaires) } & \multirow{2}{*}{$\underset{\text { participants }}{\text { All }}$} & \multicolumn{2}{|c|}{ Participants with } \\
\hline & & $B P<140 / 90 \mathrm{~mm} \mathrm{Hg}$ & $B P \geq 140 / 90 \mathrm{~mm} \mathrm{Hg}$ \\
\hline ACEI $(n=1,660)$ & $71.9(1,193)$ & $61.2(353)^{*}$ & $76.2(559)^{*}$ \\
\hline $\operatorname{ARB}(n=1,619)$ & $22.3(361)$ & $20.6(117)$ & $23.4(169)$ \\
\hline Beta-blocker $(n=1,670)$ & $65.4(1,092)$ & & \\
\hline Beta-blocker in patients without $\mathrm{MI}(\mathrm{n}=1,634)$ & $48.4(791)$ & $56.9(330)$ & $61.3(451)$ \\
\hline Calcium channel blocker $(n=1,631)$ & $41.2(672)$ & $30.7(174)^{*}$ & $48.3(351)^{*}$ \\
\hline Diuretic $(\mathrm{n}=1,671)$ & $64.8(1,083)$ & $52.9(307)^{*}$ & $66.5(497)^{*}$ \\
\hline Alpha-blocker $(n=1,595)$ & $9.7(155)$ & $8.6(49)$ & $9.0(63)$ \\
\hline Combination drug $(n=1,620)$ & $14.9(242)$ & $11.7(67)^{*}$ & $17.1(123)^{*}$ \\
\hline
\end{tabular}

Numbers in brackets - number of valid questionnaires; * significant difference between patients with and without blood pressure (BP) control; ACEI — angiotensin converting enzyme inhibitor; ARB - angiotensin receptor blocker

beta-blocker in patients with previous myocardial infarction [90.8\% of this population received this drug]). However, it should be mentioned that $60 \%$ of patients without CAD received ASA. It is not clear if ASA was used as primary prevention in these cases or if the treated patients suffered from other CVD. There is much inconsistency about ASA use in primary prevention. Diabetes Poland guidelines $[6,7,9]$ recommended ASA if 10 -year CAD risk is $>5 \%$. ESC guidelines on prevention [2] do not recommend the use ASA in T2DM patients without clinical evidence of atherosclerotic disease (class of recommendation III, level of evidence A). The most recent ESC guidelines recommend considering ASA in high-risk patients with DM on an individual basis (class of recommendation IIb, level of evidence C). This inconsistency of guidelines may contribute to possible overuse of ASA for primary prevention in T2DM in our study.

Finally, it is necessary to mention that management of $\mathrm{CV}$ risk factors in diabetic patients is challenging and is regarded as unsatisfactory not only in Poland but also in other countries from EU and outside Europe [19-24]. Of note, it was observed by Polish researchers [25] that control of CV risk factors was better in CAD patients than in diabetic patients, although still unsatisfactory in most of them; it shows that DM is still not perceived as dangerous and life-threatening as CAD. 


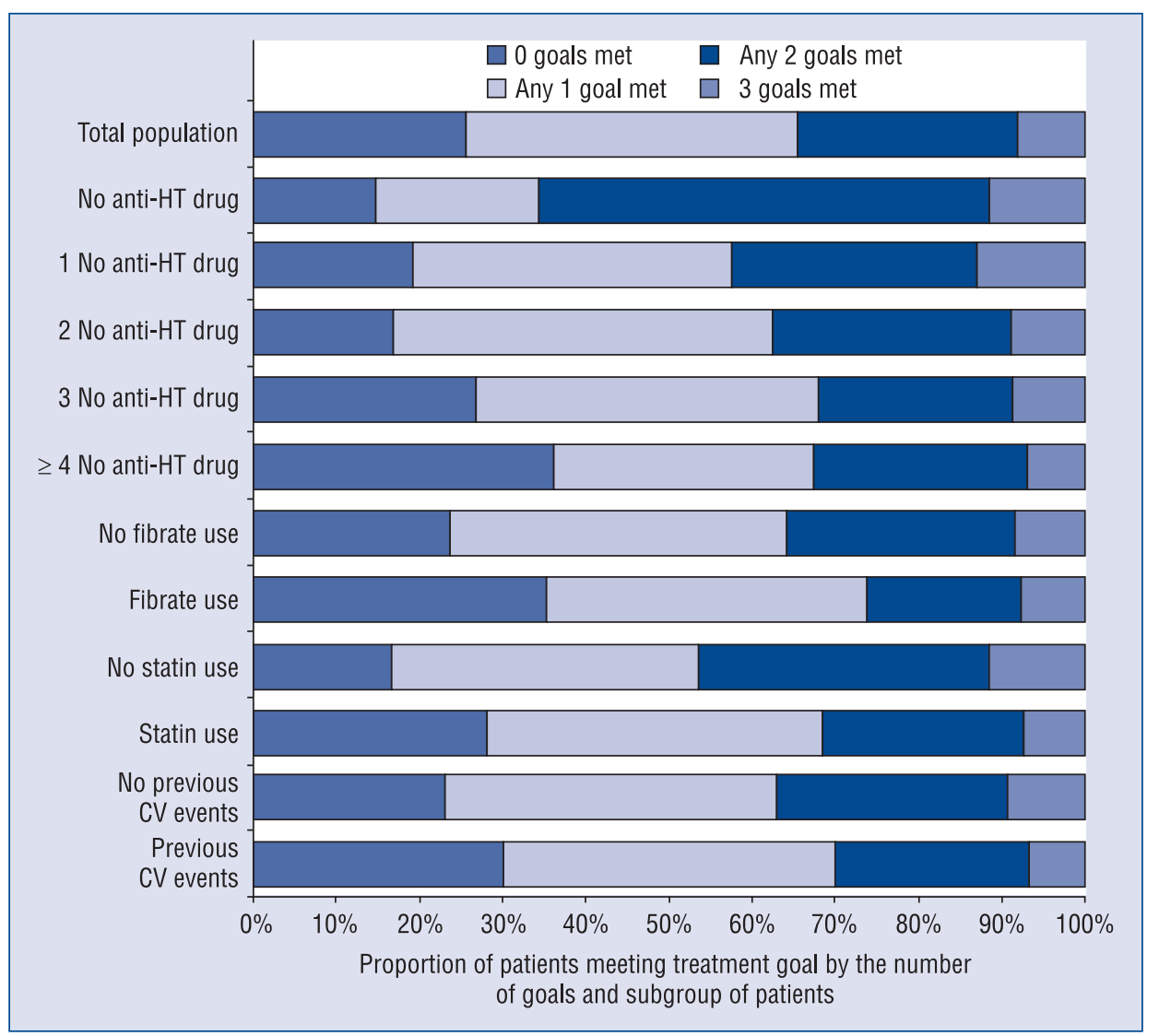

Figure 3. Number of treatment goals met in the different subgroups of ARETAEUS2-Grupa Study; CV — cardiovascular; HT - hypertensive.

\section{Limitation of the study}

Obviously, we realize that our study is not free from limitations. The cross-sectional design of the study does not provide us with long-term data. As a result of the different T2DM durations in the participants, the median or mean values of the parameters may not be informative. To get the representative sample of the population with T2DM of more than 10-year duration we randomly selected physicians participating in our study separately from diabetologists and non-diabetologists (stratified by size of the place of residence) and we introduced patient selection on a pseudo-random basis.

However, the data collected from the physicians were not verified and this may be associated with bias toward better results.

Another limitation is the fact that hypertension and lipid disorders were recognized on the basis of physician's opinion as well as the use of antihypertensive or hypolipidemic agents, respectively. This fact and the long duration of diabetes may be the reasons why the hypertension was recognized more often in our population than in other studied groups with diabetes.

\section{Conclusions}

The results of the ARETAEUS2-Grupa Study provide valuable information about $\mathrm{CV}$ risk factors prevalence and $\mathrm{CV}$ risk management in T2DM of more than 10-year duration. This information is useful for all people engaged directly or indirectly in the care of T2DM patients: doctors, nurses, university tutors and experts developing and implementing practice guidelines in Poland and other countries. It is obvious that new less restrictive treatment goals would be reached more frequently but significant improvement may still be achieved in the field of clinical practice guidelines implementation and CV prevention in T2DM population. Another component of successful treatment in chronic diseases is patients' awareness of the treatment goals, and more effort should be put into increasing compliance of the patients. It is also essential to elaborate the 
strategies to improve medical care in T2DM and surveillance of preventive-care practices and treatment goals among affected individuals for planning further initiatives that would reduce the burden of $\mathrm{CV}$ complications in T2DM patients.

\section{Acknowledgments}

We would like to thank the members of the ARETAEUS2 Scientific Committee not listed as the authors by name: Prof. Władysław Grzeszczak, MD, PhD, Prof. Leszek Czupryniak, MD, $\mathrm{PhD}$, Prof. Maria Górska, MD, PhD, Prof. Maciej Małecki, MD, PhD and Prof. Bogna Wierusz-Wysocka, MD, PhD. We would like to thank the physicians participating in the study for their effort and contribution.

\section{The ARETAEUS2 Study Group}

Scientific Committee: Prof. Jacek Sieradzki, MD, PhD (Chair), Prof. Waldemar Banasiak MD, $\mathrm{PhD}$ (Heart Disease Centre, Military Clinical Hospital, Wrocław, Poland), Prof. Leszek Czupryniak, $\mathrm{MD}, \mathrm{PhD}$ (Department of Internal Medicine and Diabetology, Medical University, Lodz, Poland), Prof. Maria Górska, MD, PhD (Department of Endocrinology, Diabetology and Internal Medicine, Medical University of Bialystok, Bialystok, Poland), Prof. Władysław Grzeszczak MD, PhD (Department of Internal Medicine, Diabetology and Nephrology, Medical University of Silesia, Zabrze, Poland), Prof. Maciej Małecki, MD, PhD (Department of Metabolic Diseases, Medical College, Jagiellonian University, Krakow, Poland), Prof. Bogna Wierusz-Wysocka, MD, PhD (Department of Internal Medicine and Diabetology, Poznan University of Medical Sciences).

Writing Group: W. Leśniak, M.M. Bała, E. Płaczkiewicz-Jankowska, R. Topór-Mądry, M. Jankowski, J. Sieradzki, W. Banasiak.

Conflict of interest: The study was funded by unrestricted educational grant from TEVA Pharmaceuticals Poland. The company had no role in the design of the questionnaire, collection, analysis and interpretation of the data.

\section{References}

1. Rydén L, Grant PJ, Anker SD et al. ESC Guidelines on diabetes, pre-diabetes, and cardiovascular diseases developed in collaboration with the EASD: The Task Force on diabetes, pre-diabetes, and cardiovascular diseases of the European Society of Cardiology (ESC) and developed in collaboration with the European Association for the Study of Diabetes (EASD). Eur Heart J, 2013; 34: 3035-3087.
2. Perk J, de Backer G, Gohlke H et al. European guidelines on cardiovascular disease prevention in clinical practice (version 2012): The Fifth Joint Task Force of the European Society of Cardiology and other societies on cardiovascular disease prevention in clinical practice (constituted by representatives of nine societies and by invited experts). Developed with the special contribution of the European Association for Cardiovascular Prevention and Rehabilitation (EACPR). Eur Heart J, 2012; 33: 1635-1701.

3. Mancia G, Fagard R, Narkiewicz K et al. 2013 ESH/ESC guidelines for the management of arterial hypertension: The Task Force for the Management of Arterial Hypertension of the European Society of Hypertension (ESH) and of the European Society of Cardiology (ESC). Eur Heart J, 2013; 34: 2159-2219.

4. Bała MM, Płaczkiewicz-Jankowska E, Topór-Mądry R et al. Do patients with recently diagnosed type 2 diabetes reach recommended treatment targets? Results of Polish ARETAEUS1 Study. Pol Arch Med Wewn, 2011; 121: 7-17.

5. Bala M, Leśniak W, Płaczkiewicz-Jankowska E et al. Cardiovascular risk factors control in Polish patients with type 2 diabetes within the first two years of diagnosis: Results of the ARETAEUS 1 study. Kardiol Pol, 2011; 69: 1249-1257.

6. Diabetes Poland. Clinical recommendations for the management of patients with diabetes 2011. Statement of Diabetes Poland. Diabetol Dośw Klin, 2011; 11: Suppl. A.

8. Bala M, Płaczkiewicz-Jankowska E, Leśniak W et al. Management and treatment goals in Polish patients with type 2 diabetes of short duration: Results of ARETAEUS2-Grupa Study. Pol Arch Med Wewn, 2013; 123: 573-581.

7. Diabetes Poland. Clinical recommendations for the management of patients with diabetes, 2012. Diabetol Klin, 2012; 1: Suppl. A.

9. Polskie Towarzystwo Diabetologiczne. Zalecenia kliniczne dotyczące postępowania u chorych na cukrzycę, 2013. Diabetol Klin, 2013; 2: Suppl. A.

10. Bała MM, Płaczkiewicz-Jankowska E, Leśniak W et al. Management and treatment goals in Polish patients with type 2 diabetes of more than ten years' duration: Results of ARETAEUS2-Grupa Study. Endokrynol Pol, 2014; 65: 158-168.

11. Diabetes Poland. Clinical recommendations for the management of patients with diabetes 2010. Statement of Diabetes Poland. Diabetol Prakt, 2010; 11: Suppl. A.

12. Jankowski M, Bała MM, Płaczkiewicz-Jankowska E et al. Specialty outpatient care of diabetic patients in Poland: Are we far from treatment targets? Rationale, design, and preliminary results of the OPTIMO study. Pol Arch Med Wewn, 2011; 121: 375-383.

13. Sieradzki J, Kasperska-Czyżyk T, Grzeszczak W et al. National results of the DYNAMIC2 (II) study. Diabetol Prakt, 2003; 4: 103-111.

14. Witek PW, Wołkow P, Stancell-Możwiłło J et al. The Polish Diabetes Registry for adults: A pilot study. Diabetol Klin, 2012; 1: 3-11.

15. Graham I, Atar D, Borch-Johnsen K et al. European guidelines on cardiovascular disease prevention in clinical practice: executive summary: Fourth Joint Task Force of the European Society of Cardiology and Other Societies on Cardiovascular Disease Prevention in Clinical Practice (Constituted by representatives of nine societies and by invited experts). Eur Heart J, 2007; 28: 2375-2414.

16. Gupta AK, Arshad S, Poulter NR. Compliance, safety, and effectiveness of fixed-dose combinations of antihypertensive agents: A meta-analysis. Hypertension, 2010; 55: 399-407.

17. Andel M, Grzeszczak W, Michalek J et al. A multinational, multicentre, observational, cross-sectional survey assessing diabetes 
secondary care in Central and Eastern Europe (DEPAC Survey). Diabet Med, 2008; 25: 1195-1203.

18. Stone NJ, Robinson JG, Lichtenstein AH et al. 2013 ACC/AHA guideline on the treatment of blood cholesterol to reduce atherosclerotic cardiovascular risk in adults: A report of the American College of Cardiology/American Heart Association Task Force on Practice Guidelines. Circulation, 2014; 29 (25 Suppl. 2): S1-45.

19. Vaccaro O, Boemi M, Cavalot $\mathrm{F}$ et al. The clinical reality of guidelines for primary prevention of cardiovascular disease in type 2 diabetes in Italy. Atherosclerosis, 2008; 198: 396-402.

20. Banegas JR, Lopez-Garcia E, Dallongeville J et al. Achievement of treatment goals for primary prevention of cardiovascular disease in clinical practice across Europe: The EURIKA study. Eur Heart J, 2011; 32: 2143-2152.

21. Ruckert IM, Schunk M, Holle R et al. Blood pressure and lipid management fall far short in persons with type 2 diabetes: Re- sults from the DIAB-CORE Consortium including six German population-based studies. Cardiovasc Diabetol, 2012; 11: 1-14.

22. Ali MK, McKeever Bullard K, Saaddine JB et al. Achievement of Goals in U.S. Diabetes Care, 1999-2010. N Engl J Med, 2013; 368: 1613-1624.

23. Braga MFB, Casanova A, Teoh $\mathrm{H}$ et al. Treatment gaps in the management of cardiovascular risk factors in patients with type 2 diabetes in Canada. Can J Cardiol, 2010; 26: 297-302.

24. Perez CM, Febo-Vázquez I, Guzmán M et al. Are adults diagnosed with diabetes achieving the american diabetes association clinical practice recommendations? PR Health Sci J, 2012; 31: 18-23.

25. Opolski G, Strojek K, Kurzelewski M et al. Cardiovascular therapy, diagnostic procedures, and control of risk factors in patients with diabetes or coronary artery disease in Poland: The Kardia-Pol Registry. Pol Arch Med Wewn, 2012; 122: 413-421. 